\title{
Seasonal Influence on Moisture Interpretation for Transformer Ageing Assessment
}

DOI:

10.1109/MEl.2016.7527123

\section{Document Version}

Accepted author manuscript

Link to publication record in Manchester Research Explorer

\section{Citation for published version (APA):}

Tee, S. J., Liu, Q., Wang, Z., Wilson, G., Jarman, P., Hooton, R., Walker, D., \& Dyer, P. (2016). Seasonal Influence on Moisture Interpretation for Transformer Ageing Assessment. IEEE Electrical Insulation Magazine, 32(3), 29-37. https://doi.org/10.1109/MEl.2016.7527123

\section{Published in:}

IEEE Electrical Insulation Magazine

\section{Citing this paper}

Please note that where the full-text provided on Manchester Research Explorer is the Author Accepted Manuscript or Proof version this may differ from the final Published version. If citing, it is advised that you check and use the publisher's definitive version.

\section{General rights}

Copyright and moral rights for the publications made accessible in the Research Explorer are retained by the authors and/or other copyright owners and it is a condition of accessing publications that users recognise and abide by the legal requirements associated with these rights.

\section{Takedown policy}

If you believe that this document breaches copyright please refer to the University of Manchester's Takedown Procedures [http://man.ac.uk/04Y6Bo] or contact uml.scholarlycommunications@manchester.ac.uk providing relevant details, so we can investigate your claim.

\section{OPEN ACCESS}




\title{
Seasonal Influence on Moisture Interpretation for Transformer Ageing Assessment
}

Key words: transformer, seasonal influence, temperature, moisture, breakdown voltage, IEC 60422

\author{
S.J. Tee, Q. Liu and Z.D. Wang \\ School of Electrical and Electronic Engineering, The University of Manchester, Manchester, M13 9PL, UK
}

G. Wilson, P. Jarman and R. Hooton

The National Grid Company, Warwick, CV34 6DA, UK

D. Walker

Scottish Power, Blantyre, G72 OHT, UK

P. Dyer

UK Power Networks, Crawley, RH10 OFL, UK

In this article, moisture in oil and seasonal factors influencing the trend of Kraft paper insulated, mineral oil filled in-service free breathing power transformers, operating at $275 \mathrm{kV}$ and $400 \mathrm{kV}$ are explored and addressed to better interpret moisture results for more accurate ageing assessment of in-service transformers.

\section{Introduction}

Ageing of power transformers is one of the biggest challenges electrical utilities face. As transformers are commissioned, their insulation system comprising of liquid (oil) and solid (paper and pressboard) insulations will deteriorate over time, jeopardising longevity and reliability of transformers. As a mean for optimising capital expenditure without undermining the reliability of electricity supply, transformer ageing or condition assessment, has been a key practice for utilities. In most cases, it stems from interpreting the measurements of different parameters that can be tested from transformer oil. One such parameter is moisture in oil which is one of the most commonly measured parameter by the UK utilities [1].

Ingress of moisture from the atmosphere represents a source of moisture in free breathing transformers [2], but with the introduction of hermetically sealed transformers, or the implementation of silica gel dryers in free breathing transformers [3], the main source of moisture is from transformer insulation ageing. Oxidation, which is the primary ageing mechanism for the liquid insulation, typically mineral oil, will produce moisture particularly when hydroxyl radicals react with hydrocarbon molecules in the branching stage of oil oxidation [4-6]. As for the solid insulation, typically Kraft paper, initial oxidation and the subsequently dominant acid-catalysed hydrolysis will also produce moisture through the cleaving of inter-unit linkages in cellulose or hemicellulose [2],[7-10].

Moisture is deleterious to both liquid and solid insulations. It is well documented that moisture present in insulating oil distorts electric field distribution, increases the electrical conductivity of the oil, and ultimately decreases the breakdown voltage of the oil, indicating lower effectiveness of the oil as a dielectric [11-20]. As for the solid insulation, moisture which is both a product from and a trigger to acid catalysed hydrolysis thus further accelerates paper decomposition [2],[7-9],[21], undermining not just its dielectric strength [3],[22], but also more significantly its mechanical strength in terms of tensile, bursting and folding strengths [23-26].

Knowing that insulation ageing produces moisture and considering its detrimental effects, 
moisture present in transformer insulation needs to be monitored. With appropriate control of moisture ingress from atmosphere, moisture could be a good transformer ageing indicator. In that context, moisture in oil is typically measured for in-service transformers. This is attributed to the relative ease of accessing transformer oil and the availability of equilibrium curves for relating the moisture in oil measurements to moisture in paper [27],[28]. Moisture in oil is customarily measured in laboratory using Karl Fischer (KF) titration. With measurements performed, subsequent action often involves interpreting measurement results into estimating transformer insulation condition. This is achieved via the reference to an international standard, such as IEC 60422 [29].

As can be interpreted from Table 1, oil temperature plays a role in the interpretation of moisture in oil measurements; more so considering that ambient temperature and loading level will change for in-service operating transformers. As a matter of fact, scattered nature of moisture measurements is seen from in-service transformers with oil temperature exerting an influence [19],[30-33]. Research has indicated that there is a commensurate increase in moisture content in oil with increasing oil temperature [19],[30],[33]. Transformer oil which is relatively hydrophobic will start having a greater affinity to moisture and hence a greater moisture solubility with increasing temperature [21],[34]. With partitioning between oil and paper, the greater moisture solubility of the oil would mean moisture that has previously been residing in paper will migrate more from the paper to the oil, thereby increasing the moisture content in oil [21].

Table 1. Interpretation of moisture measurements by IEC 60422 [29],[35].

\begin{tabular}{|c|c|c|c|c|c|}
\hline \multirow{2}{*}{$\begin{array}{c}\text { IEC } 60422 \\
\text { Versions }\end{array}$} & \multirow{2}{*}{ Moisture ( $\mathrm{mg} \mathrm{H}_{2} \mathrm{O} / \mathrm{kg}$ oil or ppm) } & \multirow{2}{*}{ Voltage $(\mathrm{kV})$} & \multicolumn{3}{|c|}{ Condition Classification } \\
\hline & & & Good & Fair & Poor \\
\hline \multirow{3}{*}{2005} & \multirow{3}{*}{$\begin{array}{l}\text { Value to be corrected to an } \\
\text { equivalent value at } 20^{\circ} \mathrm{C}\end{array}$} & $>170$ & $<5$ & $5-10$ & $>10$ \\
\hline & & $72.5-170$ & $<5$ & $5-15$ & $>15$ \\
\hline & & $\leq 72.5$ & $<10$ & $10-25$ & $>25$ \\
\hline \multirow{3}{*}{2013} & \multirow{3}{*}{$\begin{array}{l}\text { Valid for transformer operating } \\
\text { temperature, correction needed if } \\
\text { oil temperature }>70^{\circ} \mathrm{C}\end{array}$} & $>170$ & $<15$ & $15-20$ & $>20$ \\
\hline & & $72.5-170$ & $<20$ & $20-30$ & $>30$ \\
\hline & & $\leq 72.5$ & $<30$ & $30-40$ & $>40$ \\
\hline
\end{tabular}

In this article, the moisture in oil measurements particularly from a monthly perspective will be investigated with temperature influence due to different seasons particularly of interest. The measurements are from Kraft paper insulated, mineral oil filled in-service free breathing (with silica gel breathers) UK power transformers operating at primary voltages of $275 \mathrm{kV}$ and $400 \mathrm{kV}$. Factors influencing the trend of moisture with months will be explored and addressed to better interpret moisture results for more accurate ageing assessment of in-service transformers.

\section{Monthly Moisture Measurements}

Figure 1 shows mean and standard deviation representation of the moisture results in ppm with respect to different months in a year. The entries numbers and transformers contributing to the plot are also shown. It can be seen that moisture measurements stayed lower in the first and the last few months of the year if compared with high moisture values generally recorded from June to August. Similar behaviour of moisture with respect to different months in a year was also detected in analysing in-service transformers operating at primary voltages of $33 \mathrm{kV}$ and $132 \mathrm{kV}$ in the UK but is not shown here to avoid repetition. As a matter of fact, this parabolic tendency was also observed for in-service transformers in the US and Slovenia [36],[37]. 


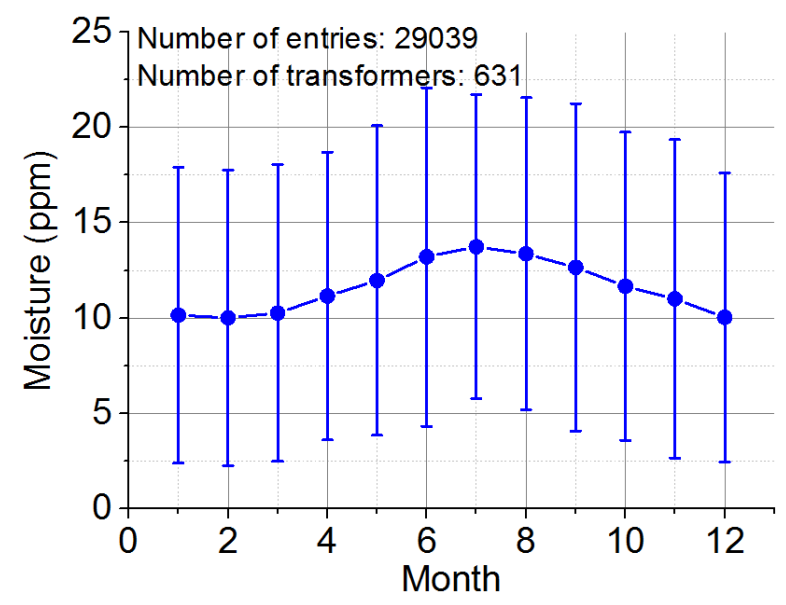

Figure 1. Monthly moisture measurements of in-service transformers.

\section{Bottom Oil Temperature and Seasonal Influence}

The parabolic tendency observed for monthly moisture measurements could be contributed by the variation in oil temperature. In Figure 2, the bottom oil temperature is shown for in-service transformers. Bottom oil temperature is analysed as oil samples are customarily obtained from the bottom drain valve of a transformer main tank. Note that not all the entries with moisture measurements have temperature records as observed from the lower number of entries if compared with that from Figure 1. Similarly to the parabolic tendency of monthly moisture measurements, bottom oil temperature does portray a parabolic tendency too, with high values in the months of June, July and August.

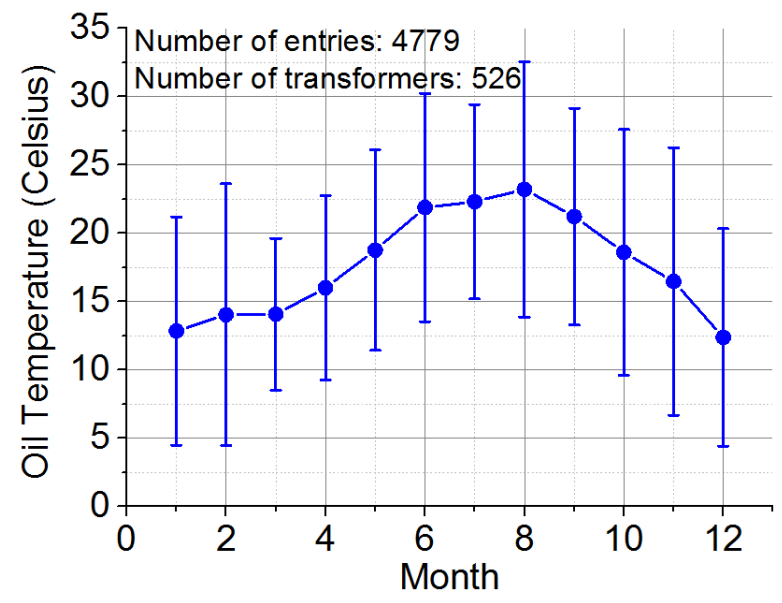

Figure 2. Monthly bottom oil temperature of in-service transformers.

With reference to [38], the bottom oil temperature is expressed by

$$
\theta_{\text {bottom }}=\theta_{\text {ambient }}+\theta_{\text {flbotr }}\left(\frac{L^{2} R_{\text {loss }}+1}{R_{\text {loss }}+1}\right)^{n}
$$

where $\theta_{\text {ambient }}$ represents ambient temperature, $\theta_{\text {flbotr }}$ denotes full load bottom oil temperature rise over ambient temperature obtained from off-line testing, $L$ is the ratio of specified load to rated load (transformer loading level), $R_{\text {loss }}$ is the ratio of rated load loss to no-load loss and $n$ symbolises cooling state constant [38]. Note that $\theta_{\text {flbotr }}, R_{\text {loss }}$ and $n$ are constants. Thus, two remaining aspects contributing to bottom oil temperature are the ambient temperature and loading level. These two aspects will be subsequently investigated for understanding their respective significance in influencing the bottom oil temperature. 
Focusing first on ambient temperature, Figure 3 illustrates the temperature profile for the city of Manchester, UK based on historical records from 1974 to 2012 [39]. Manchester is chosen as it is in the middle of the UK and perhaps could be more representative of the general UK profile. As for loading level, Figure 4 depicts a typical in-service transformer loading profile formed by evaluating half hourly actual loading records of a UK transmission transformer from January 1, 2010 to December 31, 2010.

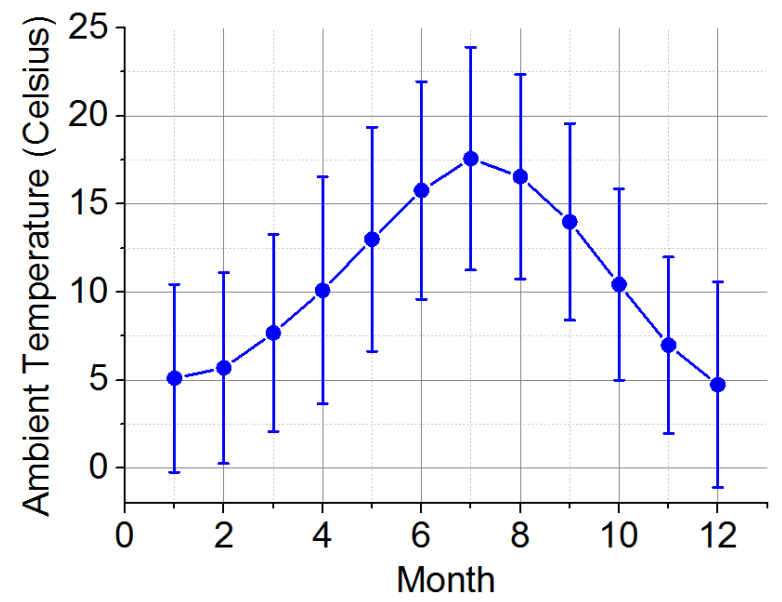

Figure 3. City of Manchester UK historical monthly ambient temperature [39].

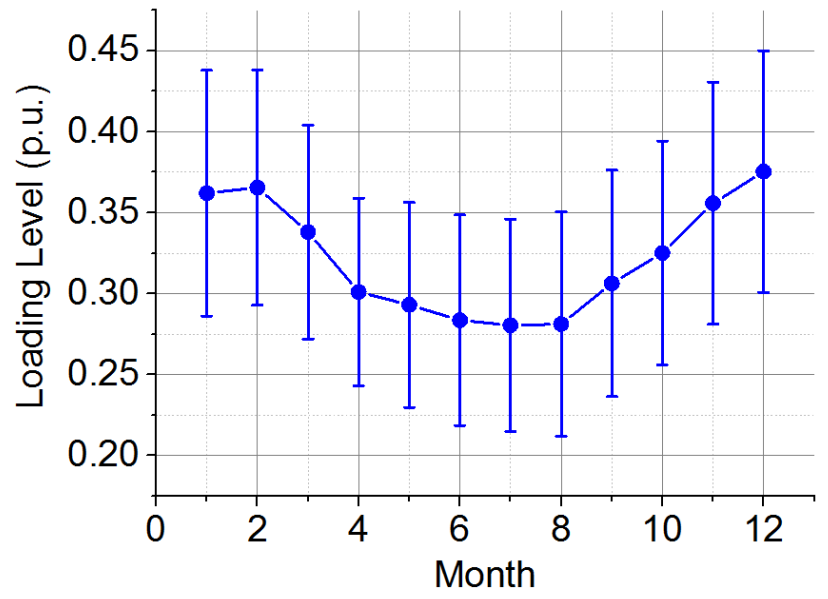

Figure 4. Typical monthly loading of a transformer.

From Figure 3 and Figure 4, during winter spanning the early and end periods of the year, the ambient temperature is low, culminating in the need for heating and hence high loading of transformers. Conversely in summer, transformers are typically more lightly loaded due to low demand for heating. Extending to the bottom oil temperature profile in Figure 2, it essentially has the same shape albeit with higher values than the ambient temperature profile. The loading level seems to just affect the bottom oil temperature more during winter and it is the seasonal variation that imparts more a dominant effect. Having established ambient temperature or seasonal influence on the bottom oil temperature, it can be extended to moisture records in Figure 1 too since high bottom oil temperature coincides with high moisture measured. Thus, seasonal influence on moisture variation is identified. 


\section{Potential Confusion in the Interpretation of Moisture}

The seasonal influence on moisture measurements could cause confusion or judgement error on the state of transformer insulation system. For instance, high moisture values detected in summer might falsely alert asset managers. This is demonstrated by Table 2 showing portions of moisture measurements of a UK in-service transformer, built in 1958, rated at $120 \mathrm{MVA}$ and operating at $275 \mathrm{kV}$.

Table 2. Snippet of moisture measurements of a UK in-service transformer.

\begin{tabular}{|c|c|c|}
\hline Sampling Date & Moisture (ppm) & Condition (IEC 60422: 2013) \\
\hline $14 / 04 / 1993$ & 11 & Good \\
\hline $02 / 06 / 1993$ & 14 & Good \\
\hline $26 / 10 / 1993$ & 13 & Good \\
\hline$\vdots$ & $\vdots$ & Good \\
\hline $30 / 01 / 1995$ & 11 & Good \\
\hline $05 / 05 / 1995$ & 14 & Fair \\
\hline $26 / 06 / 1995$ & 19 & Good \\
\hline $13 / 09 / 1995$ & 13 & Good \\
\hline $13 / 12 / 1995$ & 12 & $\vdots$ \\
\hline$\vdots$ & $\vdots$ & Good \\
\hline $17 / 01 / 2011$ & 10.5 & Good \\
\hline $18 / 04 / 2011$ & 14 & Poor \\
\hline $04 / 07 / 2011$ & 24 & Fair \\
\hline $25 / 10 / 2011$ & 17.5 & \\
\hline
\end{tabular}

Owing to the absence of oil temperature records, IEC 60422: 2013 instead of IEC 60422: 2005 was used for interpretation. In the early ageing stage, all measurements indicated a Good condition even though moisture changed from $11 \mathrm{ppm}$ to $14 \mathrm{ppm}$ before dropping back to $13 \mathrm{ppm}$ in 1993 when the transformer was 35 years old. Inherent measurement fluctuations aside, the $14 \mathrm{ppm}$ measured coincided with June which is one of the hottest months. Although there was a moisture increase, there was no change in interpreted condition throughout that single year as moisture stayed low during early ageing, all still below the Fair condition criterion.

As a transformer ages, more moisture is produced. In 1995, the transformer was still adjudged to be in a Good condition throughout the whole year except for June when it is hot. Moisture measurements of that year started with $11 \mathrm{ppm}$, increasing over time to a value of $19 \mathrm{ppm}$ in June before decreasing as the season changed. The same parabolic tendency can be perceived again in 2011 where moisture measurement peaked at $24 \mathrm{ppm}$, indicating a Poor condition in July, different from the better conditions interpreted in other periods of the year.

The observation for late ageing moisture values suggests high possibility of judgement error on insulation condition as moisture of the insulation system would have already been high and any ambient temperature increase could cause higher moisture measured indicating an even poorer condition. From asset management perspective, it is less likely to see such a sudden condition change within the same year unless there is moisture ingress. It is known that oil at a higher temperature has greater moisture solubility. Thus, the higher moisture 
could be related to a similar dielectric strength when the oil is at a lower temperature and having lower moisture.

\section{Temperature Incorporation for Moisture Interpretation}

The need for incorporating temperature in moisture interpretation, which can be done by analysing relative moisture content or relative humidity (RH), is clearly needed. This term is expressed in percentage (\%) and is the ratio of absolute moisture content to moisture solubility (saturation level) of oil [21],[29]. In addition to oil type and oil condition, moisture solubility, $W_{\text {solubility, }}$ is a function of oil temperature and thus allows incorporation of temperature information [21],[29],[40]. This temperature dependent moisture solubility, as referred from IEC 60422 [29], is

$$
W_{\text {solubility }}=10^{7.0895-1567 / T_{\text {sampling }}}
$$

where $\mathrm{T}_{\text {sampling }}$ is the oil sampling temperature in Kelvin.

Consideration of only oil temperature for moisture solubility has actually the same effect as employing a correction factor which is a term also discussed in IEC 60422 [29]. Nonetheless, moisture solubility and hence $\mathrm{RH}$ is used in this study for temperature incorporation as the breakdown voltage behaviour is generally linked to $\mathrm{RH}$ variation. Figure 5 shows $\mathrm{RH}$ results of the in-service transformers that have been considered thus far and those having oil temperature records.

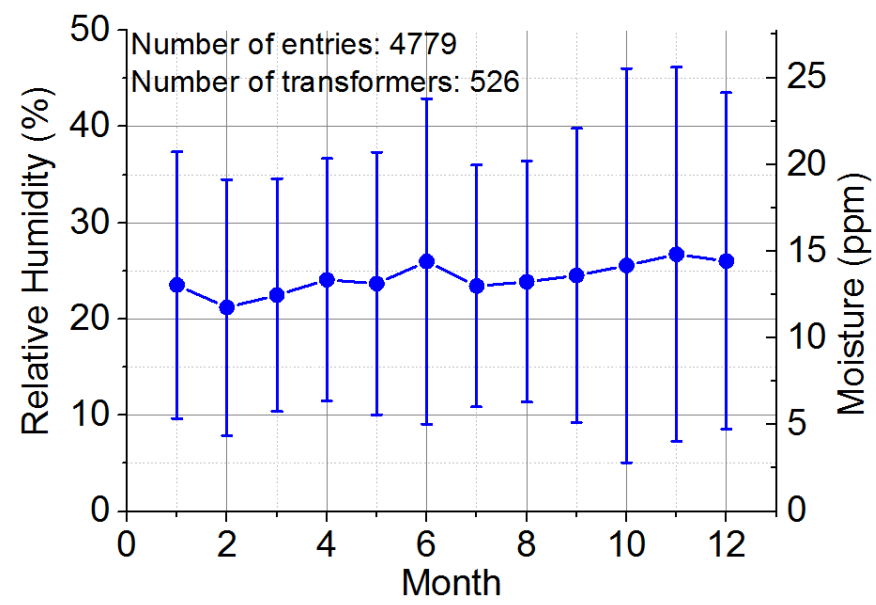

Figure 5. Monthly RH and temperature revised moisture of in-service transformers.

With oil temperature incorporated, the parabolic tendency previously evident across different months has been mitigated as perceived from Figure 5. If moisture in ppm is preferred, it can simply be calculated by multiplying the RH with moisture solubility at a set temperature, for instance, at room temperature $\left(20^{\circ} \mathrm{C}\right)$. This calculation has the same effect as the moisture correction discussed in IEC 60422:2005. The flatter trend of RH with months can also be observed from analysing online measurement data. Figure 6 shows 27203 online measurements of both oil temperature and $\mathrm{RH}$ for a particular in-service transformer fitted with an RH sensor, for 2012. As observed, oil temperature shows a parabolic tendency with months but RH stays arguably constant, more so given the smaller scale which ranges from 0 to $6 \% \mathrm{RH}$. Hence, through temperature incorporation in terms of moisture interpretation, parabolic tendency or seasonal influence can be mitigated. 


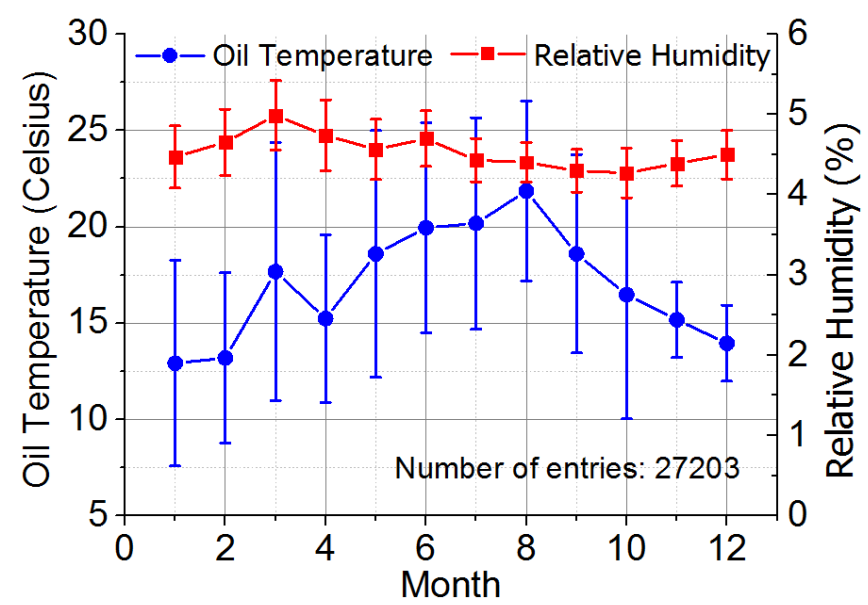

Figure 6. Monthly plot of online oil temperature and RH of an in-service transformer.

\section{Breakdown Voltage Implication}

As the breakdown voltage (BDV) is affected by moisture in oil, temperature incorporation could be extended to BDV too. This also stems from the concern that, just like moisture, BDV which is normally measured at room temperature might not truly indicate the dielectric strength of the oil at transformer operating temperatures [41],[42]. Figure 7 shows how BDV behaves with RH aggregated from different literatures. For ease of data aggregation and comparison, moisture used in all literatures was expressed in $\mathrm{RH}$, whereas BDV was expressed in per unit by dividing each BDV in kilovolt $(\mathrm{kV})$ by the highest BDV recorded [43]. Representation of BDV in per unit is to account for different electrode gap distances $(1-2.5 \mathrm{~mm})$ for BDV as reported in different sources [43].

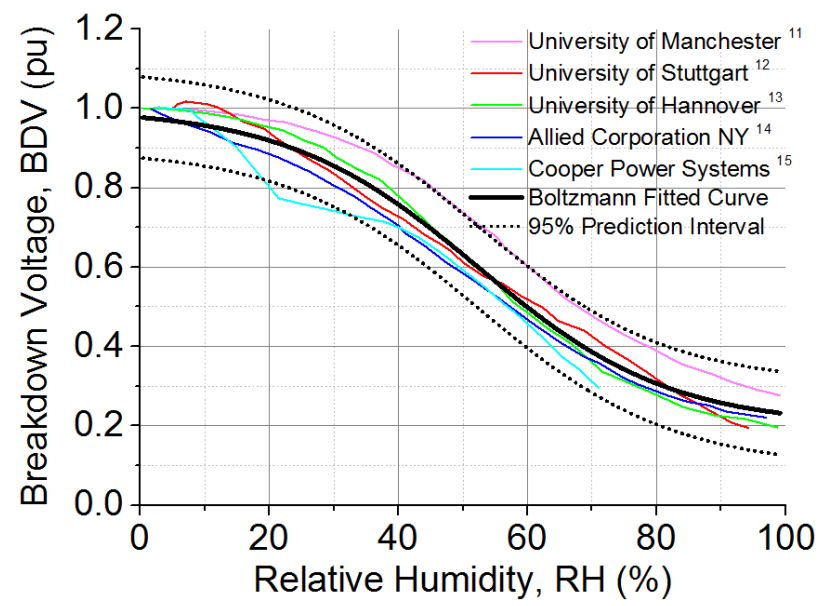

Figure 7. Behaviour of per unit BDV with RH from various sources [11-15].

The findings from literature showed that BDV reduction follows a similar trend with increase in $\mathrm{RH}$. All the findings were then represented by the Boltzmann fitted curve to produce a generic BDV vs RH curve, with an adjusted R-square value of 0.9623 . The Boltzmann equation used for fitting is as follows: 


$$
B D V=B D V_{\min }+\frac{B D V_{\max }-B D V_{\min }}{1+\exp \frac{-\left(R H_{\operatorname{midspan}}-R H\right)}{R H_{\text {@imeconstant }}}}
$$

where $B D V_{\max }$ is the maximum BDV attainable, whereas $B D V_{\min }$ limits the lowest BDV at an extremely high RH. Values of 1.0 and 0.2 were selected for $B D V_{\max }$ and $B D V_{\min }$ respectively. A value of 52.4 was assigned to $R H_{\text {midspan }}$ which denotes the $R H$ value culminating in a BDV halfway between $B D V_{\max }$ and $B D V_{\min }$ and $R H_{@ \text { timeconstant }}$ is analogous to a time constant and can be approximated by calculating the slope of the curve portion having an obvious change in BDV values [44]. This slope would then be equated with $\left(\left(B D V_{\max }-B D V_{\min }\right) /\left(4^{*}\right.\right.$

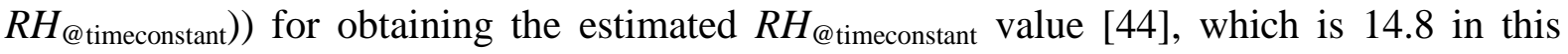
case.

Essentially, BDV decreases with increasing RH. More specifically, BDV actually changes little during initial RH increase due to the even dissolution of water through hydrogen bonding with polar species in oil [18].With increasing RH and with limited number of polar species in oil, water molecules will agglomerate to form water clusters or combine with particles; manifesting as weakest links that cause a faster decrease of BDV [18]. As moisture increases beyond the solubility limit, free water droplets appear, rendering a very low BDV [18],[45].

\section{In-service Moisture and Breakdown Voltage Example}

Table 3 shows an in-service transformer example for both moisture and BDV revisions [43]. This 1993 built UK in-service transformer is rated at 276 MVA and operating at $400 \mathrm{kV}$. The measured value of moisture was first converted into $\mathrm{RH}$ considering moisture solubility at room temperature of $55.5 \mathrm{ppm}$ as evaluated from Equation (2). Once actual oil sampling temperature was considered, moisture solubility at $57^{\circ} \mathrm{C}$ is $220.4 \mathrm{ppm}$, resulting in a RH of $9.7 \%$ which means the oil is dry.

Table 3. Original measurements and interpreted results of moisture and BDV [43].

\begin{tabular}{|c|c|c|}
\hline \multicolumn{3}{|c|}{ Oil Sampling Temperature of $57{ }^{\circ} \mathrm{C}$} \\
\hline \multirow{2}{*}{$\begin{array}{c}\text { Moisture and } \\
\text { Relative } \\
\text { Humidity (RH) }\end{array}$} & Measured & $21.5 \mathrm{ppm}$ \\
\cline { 2 - 3 } & $\mathrm{RH} @ 20^{\circ} \mathrm{C}$ & $38.7 \%$ \\
\cline { 2 - 3 } & $\mathrm{RH} @ 57^{\circ} \mathrm{C}$ & $9.7 \%$ \\
\hline \multirow{2}{*}{$\begin{array}{c}\text { Breakdown } \\
\text { Voltage (BDV) }\end{array}$} & Measured & $57 \mathrm{kV}$ \\
\cline { 2 - 3 } & $\mathrm{BDV} @ 20^{\circ} \mathrm{C}$ & $0.57 \mathrm{pu}$ \\
\cline { 2 - 3 } & & $0.76 \mathrm{pu}$ \\
\hline
\end{tabular}

As for BDV, the original measured value of $57 \mathrm{kV}$ is simply expressed in terms of $0.57 \mathrm{pu}$ by comparing it to the maximum BDV in the database $(100 \mathrm{kV})$. In order to incorporate temperature into BDV interpretation, the $\mathrm{RH}$ change due to temperature consideration (green coloured range in Figure 8) is reflected into a change in BDV (orange coloured range in Figure 8). This BDV change is subsequently added to the original BDV, resulting in a revised $\mathrm{BDV}$ of $0.76 \mathrm{pu}$, which insinuates a higher dielectric strength than initially thought. 


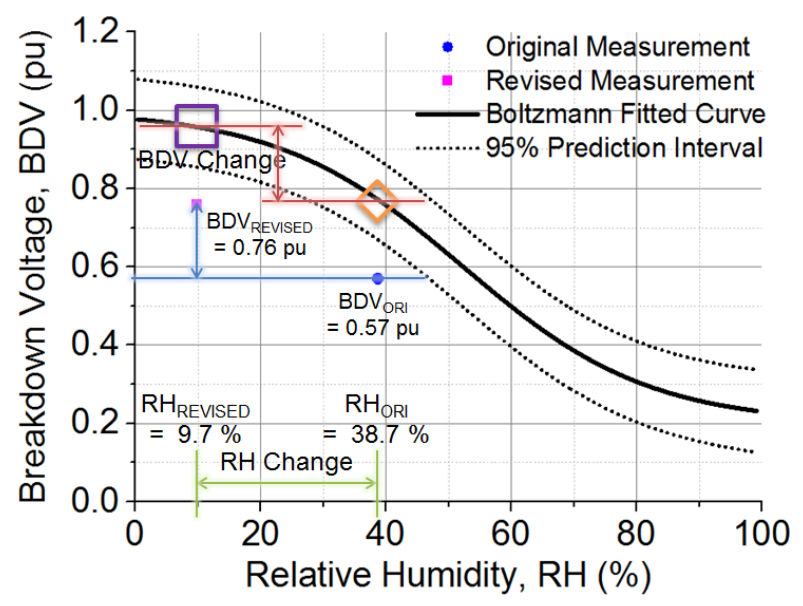

Figure 8. BDV revision based on $R H$ revision.

\section{Discussion}

Analysis of oil test databases pertaining to in-service transformers revealed seasonal influence on moisture measurements. It is potentially beneficial for other countries to be more cognisant of their respective seasonal profiles and try to address any possible moisture value fluctuations due to sampling at different months in a year. Taking the USA as an example, its seasonal profile resembles that of the UK, but with greater difference between the temperatures experienced in summer and in winter. A bigger difference in magnitude for moisture measured in summer and in winter can then be envisaged. Extending the concept to other countries like Australia, winter coincides with summer in the UK. Hence, an inverted parabolic tendency for monthly moisture measurements can be expected if compared with that of the UK. For tropical countries with relatively constant ambient temperature throughout a year, moisture might not exhibit any parabolic tendency but it is still advisable to incorporate temperature into interpreting moisture and BDV considering different loading levels.

Extending from seasonal influence, oil temperature is seen to impart a direct influence on moisture and an indirect influence on BDV. As seen from Table 3, through incorporating oil temperature, the condition of the oil is not as bad as initially interpreted. The need for oil temperature has actually been discussed in the past and recent versions of IEC 60422 [29],[35],[46],[47]. Particularly in IEC 60422:2005, moisture interpretation was stipulated based on measurements corrected to a reference temperature [35]. However, this practice has not been prevalent, at least not from most of the UK utility databases studied. Interestingly in the latest version IEC 60422:2013, interpretation based on corrected moisture values was discontinued perhaps considering the lack of oil temperature records in the field. Instead moisture interpretation is to be based on original measurements and only valid for transformer operating temperatures [29]. This appears to be a relaxation on the need for oil temperature, but knowing transformer operating temperatures vary according to load and ambient temperature (seasonal influence); oil temperature records could still be required for interpreting moisture and BDV.

The proposed moisture interpretation in terms of RH by incorporating temperature could be useful. With capacitive or resistive solid state $\mathrm{RH}$ sensors readily available, the direct records of RH can be achieved. By considering moisture solubility curve, absolute moisture values in ppm are then calculated and displayed together with the direct RH measurements. Nevertheless, with different moisture solubility curves for different oil types and different oil 
conditions, the RH sensor accuracy in predicting absolute moisture is still an ongoing debate. Considering current condition interpretation that is based on absolute moisture, the implementation of RH sensors could be more welcome if interpretation based on RH values could also be referred to.

Besides moisture measurements, BDV measured in a laboratory setting may need temperature incorporation into interpretation as well. Interestingly, there have recently been ideas on the possibility of heating the oil up to a temperature as recorded from a particular inservice transformer before testing for BDV; all considering unchanged oil condition like moisture level before and after the heating. Currently, with large databases of historical moisture and BDV records, BDV can be revised by converting a change in RH into a change in BDV; provided sampling temperature information is available. A limitation to such an approach is that BDV is not solely affected by moisture in oil, but also other factors like particles and acidity [11],[16]. Hence, a possible improvement could be to incorporate the influence of other factors into deriving a more representative BDV.

\section{Conclusion}

Transformer condition assessment is imperative for evaluating transformer usability. One of the most prevalently tested parameters is moisture in oil. By analysing UK in-service transformers, inherent moisture fluctuations could be caused by ambient temperature (seasonal) variation throughout the year and this could be mitigated by incorporating temperature into better interpreting moisture results. This temperature revised moisture can also be used for revising breakdown voltage measurements through the use of a generic relationship between breakdown voltage and relative humidity. Through the demonstrations in this paper, it is hoped that the record of oil temperature and its subsequent use in interpretation of both moisture and breakdown voltage measurements are to be fostered more widely among utilities for accurate transformer ageing assessment.

\section{Acknowledgement}

The authors would like to express their gratitude to M\&I Materials, National Grid, Scottish Power, Shell, TJ|H2b Analytical Services, UK Power Networks and Weidmann for their financial and technical contributions to the Transformer Research Consortium at The University of Manchester.

\section{References}

[1] S.J. Tee, Q. Liu, Z.D. Wang, G. Wilson, P. Jarman, R. Hooton, P. Dyer and D. Walker, "Practice of IEC 60422 in Ageing Assessment of In-Service Transformers," 19th Int'l. Sympos. High Voltage Eng. (ISH), Pilsen, Czech Republic, Paper 423, 2015.

[2] L. Lundgard, "Ageing of cellulose in mineral-oil insulated transformers," Electra, pp. 50-9, 2007.

[3] I. Fofana, H. Borsi, and E. Gockenbach, "Fundamental investigations on some transformer liquids under various outdoor conditions," IEEE Trans. Dielectr. Electr. Insul., vol. 8, issue 6, pp. 1040-1047, 2001.

[4] "Oxidation Stability of Insulating Fluids," CIGRE Brochure 526, 2013.

[5] I. Fofana, A. Bouaicha, M. Farzaneh, J. Sabau, D. Bussieres, and E. B. Robertson, "Decay products in the liquid insulation of power transformers," IET Elec. Power App., vol. 4, issue 3, pp. 177-184, 2010.

[6] S. Okabe, S. Kaneko, M. Kohtoh, and T. Amimoto, "Analysis results for insulating oil components in field transformers," IEEE Trans. Dielectr. Electr. Insul., vol. 17, issue 1, pp. 302-311, 2010. 
[7] L. E. Lundgaard, W. Hansen, D. Linhjell, and T. J. Painter, "Aging of oil-impregnated paper in power transformers," IEEE Trans. Power Delivery, vol. 19, issue 1, pp. 230239, 2004.

[8] M. H. Glomm Ese, K. B. Liland, and L. E. Lundgaard, "Oxidation of paper insulation in transformers," IEEE Trans. Dielectr. Electr. Insul., vol. 17, issue 3, pp. 939-946, 2010.

[9] N. Lelekakis, G. Wenyu, D. Martin, J. Wijaya, and D. Susa, "A field study of aging in paper-oil insulation systems," IEEE Electr. Insul. Mag., vol. 28, issue 1, pp. 12-19, 2012.

[10] P. Przybylek and H. Moscicka-Grzesiak, "The influence of water content and ageing degree of paper insulation on its mechanical strength," in 10th IEEE Int'l. Conf. Solid Dielectr. (ICSD), pp. 1-3, 2010.

[11] X. Wang and Z. D. Wang, "Study of dielectric behavior of ester transformer liquids under ac voltage," IEEE Trans. Dielectr. Electr. Insul., vol. 19, issue 6, pp. 1916-1925, 2012.

[12] S. Tenbohlen, M. Koch, D. Vukovic, A. Weinlader, S. Barker, J. Baum, et al., "Application of vegetable oil-based insulating fluids to hermetically sealed power transformers," CIGRE A2-102 in Paris, 2008.

[13] E. Gockenbach and H. Borsi, "Natural and Synthetic Ester Liquids as alternative to mineral oil for power transformers," in Conf. Electr. Insulal. and Dielectr. Phenomena CEIDP, pp. 521-524, 2008.

[14] K. Miners, "Particles and Moisture Effect on Dielectric Strength of Transformer Oil Using VDE Electrodes," IEEE Power Eng. Review, vol. PER-2, issue 3, pp. 36-36, 1982.

[15] "Envirotemp FR3 Fluid Testing Guide," C. P. Systems, 2008.

[16] M. Koch and S. Tenbohlen, "The breakdown voltage of insulation oil under the influence of humidity, acidity, particles and pressure," in Int'l. Conf Advances in Processing, Testing and App. of Dielectr. Materials APTADM, 2007.

[17] Vaisala, "The Effect of Moisture on the Breakdown Voltage of Transformer Oil", Retrieved 25 July 2014, from http://www.vaisala.com/Vaisala\%20Documents/ White\%20Papers/CEN-TIA-power-whitepaper-Moisture-and-Breakdown-Voltage-B2 11282EN-A-LOW.pdf

[18] X. Wang and Z. D. Wang, "Particle Effect on Breakdown Voltage of Mineral and Ester Based Transformer Oils," in Conf. Electr. Insulal. and Dielectr. Phenomena CEIDP,pp. 598-602, 2008.

[19] I. Atanasova-Hoehlein, U. Sundermann, M. Kuffel, and S. ETTL, "Moisture Estimation in Oil filled Equipment by Capacitive Sensors and Karl-Fischer Titration Is It the Same?," presented at the CIGRE SC D1 Materials and Emerging Test Techniques, Paris, France, 2014.

[20] L. Ruijin, L. Yuandi, G. Pei, L. Haibin, and X. Huanhuan, "Thermal aging effects on the moisture equilibrium curves of mineral and mixed oil-paper insulation systems," IEEE Trans. Dielectr. Electr. Insul., vol. 22, issue 2, pp. 842-850, 2015.

[21] Y. Du, M. Zahn, B. C. Lesieutre, A. V. Mamishev, and S. R. Lindgren, "Moisture equilibrium in transformer paper-oil systems," IEEE Electr. Insul. Mag., vol. 15, issue 1, pp. 11-20, 1999.

[22] S. Okabe, G. Ueta, and T. Tsuboi, "Investigation of aging degradation status of insulating elements in oil-immersed transformer and its diagnostic method based on field measurement data," IEEE Trans. Dielectr. Electr. Insul., vol. 20, issue 1, pp. 346-355, 2013. 
[23] P. Koestinger and T. Bruaroy, "Drying of power transformers in the field, applying the LFH-Technology in combination with oil reclamation," CIGRE, 2006.

[24] R. B. Blodgett, "Influence of Absorbed Water and Temperature on Tan Delta and Dielectric Constant of Oil-Impregnated Paper Insulation," Power Apparatus and Systems, Part III. Trans. of the American Inst. of Electr. Eng., vol. 81, issue 3, pp. 9398, 1962.

[25] B. Pahlavanpour, M. A. Martins, and A. De Pablo, "Experimental investigation into the thermal-ageing of Kraft paper and mineral insulating oil," in IEEE Int'l. Sympos. Electr. Insul., pp. 341-345, 2002.

[26] A. de Pablo, "Furfural and ageing: how are they related," in IEE Colloq. Insul. Liquids (Ref. No. 1999/119), pp. 5/1-5/4, 1999.

[27] D. Martin, T. Saha, T. Gray, and K. Wyper, "Determining water in transformer paper insulation: effect of measuring oil water activity at two different locations," IEEE Electr. Insul. Mag., vol. 31, issue 3, pp. 18-25, 2015.

[28] T. V. Oommen and T. A. Prevost, "Cellulose insulation in oil-filled power transformers: part II maintaining insulation integrity and life," IEEE Electr. Insul. Mag., vol. 22, issue 2, pp. 5-14, 2006.

[29] "IEC 60422 Mineral insulating oils in electrical equipment - Supervision and maintenance guidance (Edition 4.0)," International Electrotechnical Commission (IEC) - Fluids for Electrotechnical Applications Technical Committee, p. 93, 2013.

[30] A. Muller, M. Jovalekic, and S. Tenbohlen, "Assessment of Oil Analysis Data for Medium Voltage Distribution Transformers," presented at the XVII Int'l. Sympos. High Voltage Eng. Hannover, Germany, 2011.

[31] Z. Xiang and E. Gockenbach, "Determination of the thermal aging factor for life expectancy of $550 \mathrm{kV}$ transformers with a preventive test," IEEE Trans. Dielectr. Electr. Insul., vol. 20, issue 6, pp. 1984-1991, 2013.

[32] N. Azis, D. Zhou, Z. D. Wang, D. Jones, B. Wells, and G. M. Wallwork, "Operational condition assessment of in-service distribution transformers," in Int'1. Conf. Condition Monitoring and Diagnosis CMD, pp. 1156-1159, 2012.

[33] J. Jalbert, M. C. Lessard, and M. Ryadi, "Cellulose chemical markers in transformer oil insulation Part 1: Temperature correction factors," IEEE Trans. Dielectr. Electr. Insul., vol. 20, issue 6, pp. 2287-2291, 2013.

[34] B. Garcia, J. C. Burgos, A. M. Alonso, and J. Sanz, "A moisture-in-oil model for power transformer monitoring - Part I: Theoretical foundation," IEEE Trans. Power Delivery, vol. 20, issue 2, pp. 1417-1422, 2005.

[35] "IEC 60422 Mineral insulating oils in electrical equipment - Supervision and maintenance guidance (Edition 3.0)," International Electrotechnical Commission (IEC) - Fluids for Electrotechnical Applications Technical Committee, p. 85, 2005.

[36] C. Beauchemin, "Example of moisture in oil," Transformer Moisture Committee Task Force, San Diego: TJ|H2b, 2011.

[37] T. Gradnik, B. CuČek, and M. KonČan-Gradnik, "Estimating moisture content in oilfilled power transformers: in-service experience," Milan Vidmar Power Research Institute (EIMV), Slovenia: CIGRE, 2014.

[38] M. A. Taghikhani, "Power Transformer Winding Thermal Analysis Considering Load Conditions and Type of Oil," Int'l. Journal of Material and Mechanical Eng., vol. 1, 2012.

[39] WeatherSpark, "Average Weather For Manchester, United Kingdom", Retrieved 25 July 2014 from http://weatherspark.com/averages/28702/ Manchester-EnglandUnited-Kingdom, 2014. 
[40] G. D. Golovan, T. B. Zhilyaev, A. I. Panchenko, and V. S. Kriven'kaya, "Water solubility in transformer oils with various hydrocarbon compositions," Chemistry and Technology of Fuels and Oils, vol. 20, issue 8, pp. 387-391, 1984.

[41] S.J. Tee, Q. Liu, Z.D. Wang, G. Wilson, P. Jarman, R. Hooton, D. Walker and P. Dyer, "Challenges in Oil Test Database Analysis for Ageing Assessment of InService Transformers," 50th Int'1. Universities Power Eng. Conf. (UPEC), Stoke-onTrent, UK, Paper 110, 2015.

[42] Z.D. Wang, Q. Liu, S.J. Tee, S.Y. Matharage, P. Jarman, G. Wilson, R. Hooton, P. Dyer, D. Walker, Ch. Krause, P.W.R. Smith, P. Mavrommatis and A. Gyore," Ageing Assessment of Transformers through Oil Test Database Analyses and Alternative Diagnostic Techniques," CIGRE SC A2 Colloquium, Shanghai, China, Paper FP0663, 2015.

[43] S.J. Tee, Q. Liu, and Z.D. Wang, "Prognosis of Transformer Health through Oil Data Analysis," TechCon® Euro, 2013, Glasgow, UK, 2013.

[44] (OriginLab, "Boltzmann", Retrieved 28 October 2014, from http://www.originlab. com/doc/Origin-Help/Fitting-Sigmoidal, 2014.

[45] Y. Du, A. V. Mamishev, B. C. Lesieutre, M. Zahn, and S. H. Kang, "Moisture solubility for differently conditioned transformer oils," IEEE Trans. Dielectr. Electr. Insul., vol. 8, issue 5, pp. 805-811, 2001.

[46] "IEC 60422 Mineral insulating oils in electrical equipment - Supervision and maintenance guidance (Edition 1.0)," International Electrotechnical Commission (IEC) - Fluids for Electrotechnical Applications Technical Committee, p. 32, 1973.

[47] "IEC 60422 Mineral insulating oils in electrical equipment - Supervision and maintenance guidance (Edition 2.0)," International Electrotechnical Commission (IEC) - Fluids for Electrotechnical Applications Technical Committee, p. 71, 1989.

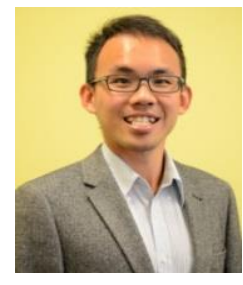

Shengji Tee received his B.Sc. degree in electrical and electronics engineering (2011) from Universiti Tenaga Nasional in Malaysia and his M.Sc. degree in electrical power systems engineering from The University of Manchester in the United Kingdom. He is currently studying for a Ph.D. degree in the Electrical Energy and Power Systems Group in the School of Electrical and Electronic Engineering at The University of Manchester. His research interests are on transformer ageing assessment and asset management.

Email: shengji.tee@postgrad.manchester.ac.uk

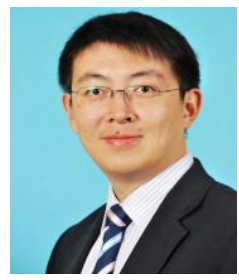

Qiang Liu (S'08-M'12) obtained the B.Eng. degree in electrical engineering (2005) and the M.Eng. degree in high voltage and electrical insulation (2008) from Xi'an Jiaotong University in China, and the Ph.D. degree in electrical power engineering (2011) from The University of Manchester in the UK. Currently he is a Lecturer in the Electrical Energy and Power Systems Group in the School of Electrical and Electronic Engineering at The University of Manchester. His research interests are on pre-breakdown and breakdown phenomena in liquids, ester transformer liquids, streaming electrification, ageing of insulating materials, transformer asset management and high voltage testing. Email: qiang.liu@manchester.ac.uk

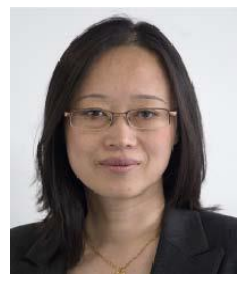

Zhongdong Wang received the B.Eng. and the M.Eng. degrees in high voltage engineering from Tsinghua University of Beijing in 1991 and 1993 respectively and the Ph.D. degree in electrical engineering from UMIST in 1999. Currently she is a Professor of High Voltage Engineering at the Electrical Energy and Power Systems Group of the School of Electrical and Electronic Engineering at The University of Manchester. Her current research interests include transformer condition monitoring, transformer modelling, FRA, transients' simulation, insulation ageing and alternative insulation materials for transformers. Email: zhongdong.wang@manchester.ac.uk 


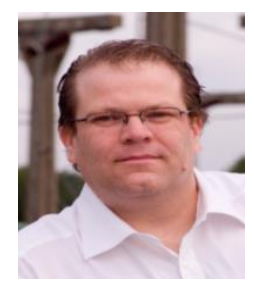

Gordon Wilson (M'08) completed his chemistry degree at the University of Surrey, UK in 1995. This was followed by a National Grid-sponsored Ph.D. degree in characterizing mineral transformer oil, also at the University of Surrey. He joined National Grid in 1999 as an oil chemist providing support to a team of transformer specialists. Since 2007 he has worked on transformer thermal ratings whilst retaining responsibility for transformer oil issues. He is a member of BSi National Committee GEL/10 for electrotechnical fluids and CIGRE Advisory Group D1.01 for liquid and liquid impregnated insulation systems and he has represented the UK in a number of IEC and CIGRE groups related to oil and ratings. Email: gordon.wilson@uk.ngrid.com

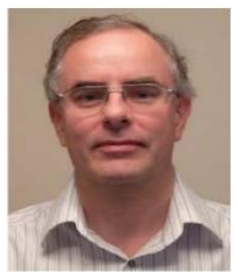

Paul Jarman was born in London on 27 September 1962, and graduated from Cambridge University in 1984 with an Honours degree in electrical science. He joined the Central Electricity Generating Board, Research Division, working on, amongst other projects, FRA testing of transformers. In 1990, he joined the National Grid as a transformer engineer, becoming head of transformers in 1998. Since 2001, Jarman has been National Grid's technical specialist for transformers now within the Asset Management group. Jarman is chairman of IEC TC14, the international committee for power transformer standards; is the UK regular member of CIGRE study committee A2 for transformers; and has recently been the convenor of a CIGRE group on transformer monitoring. He is a chartered electrical engineer and member of the IET. Email: paul.jarman@uk.ngrid.com

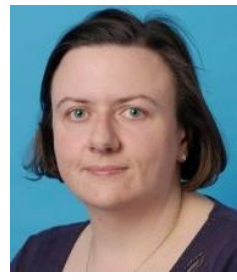

Ruth Hooton is a graduate of the Queen's University of Belfast (1994) and Erasmus University, Rotterdam (2000), a Sainsbury Management Fellow and a Chartered Electrical Engineer. Since 1995 she has held a range of roles within National Grid and is currently employed as the Transformer Policy Specialist in National Grid's Electricity Transmission Business. She is a member of CIGRE WG A2-45. Email: ruth.hooton@ nationalgrid.com

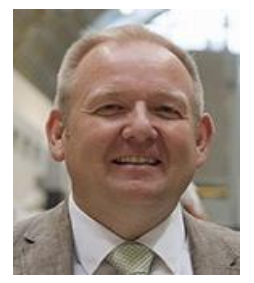

David Walker is the Lead Engineer for Transformers within the Engineering Design \& Standards group of SP EnergyNetworks, and has responsibility for transformers and reactors from $11 \mathrm{kV}$ to $400 \mathrm{kV}$ and $25 \mathrm{kVA}$ to $1000 \mathrm{MVA}$. David joined the South of Scotland Electricity Board (SSEB), now ScottishPower, from school in 1982 and has more than 30 years' experience in operations, maintenance, construction and protection. David completed his craft apprenticeship in 1986 and engineering training in 1991. David has a HNC in Electric and Electronic Engineering from Bell College 1988 and CBA from Glasgow University 1998. David represents the Energy Networks Association (ENA) on two BSI committees, PEL14, Power transformers and GEL10, Fluids for electrotechnical applications and also attends IEC TC10 and TC14 on their behalf, David is a member of IEC TC14 WG32. David is an individual member of CIGRE and is currently on two working groups, A2.49 Condition Assessment of Power Transformers and A2.48 Technology and Utilisation of Oil Insulated HV Shunt Reactors.

Email: David.Walker2@spenergynetworks.co.uk

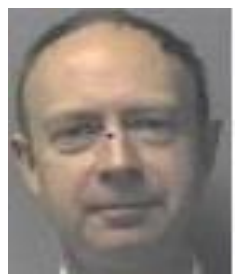

Paul Dyer joined the U.K. Electricity supply as a Student Apprentice with the London Electricity Board. After 5 years training he took up a position as a Commercial Engineer and from there moved to the System Operations branch. He has held various positions as an Engineer in the activities of London Electricity involving maintenance, operations, installation, and commissioning of low and high voltage electrical equipment. He moved to the Asset Management department and took up a position of Asset Performance Manager for London Electricity where he was responsible for the assessment of the performance of the Network equipment and making recommendations for its improvement. He then took up the position of Technical Manager responsible for the assessment and approval of the network equipment. He is now responsible for the specifications, assessment and approvals of transformers and Switchgear for UK Power Networks. Paul is a Chartered Electrical Engineer, Fellow of the Institution of Engineering and Technology, a Fellow of the Institution of Plant Engineers and a Fellow of the Society of Operations Engineers. Email: paul.dyer@ukpowernetworks.co.uk 